\title{
Propiedad, infraestructura y conservación como mecanismos de exclusión en el proceso de desarrollo turístico en la costa de Oaxaca, México
}

\author{
Ignacio Rubio \\ Universidad Nacional Autónoma de México, México \\ (iD) https://orcid.org/0000-0002-3562-6359 \\ irubio@politicas.unam.mx
}

\section{Introducción}

Para poder realizarse, el turismo de playa requiere la producción de espacios de consumo del paisaje biocultural. La organización de los servicios y actividades que conforman el consumo turístico no aparece de manera espontánea, no es la respuesta mecánica a una demanda imparcial del mercado, al menos no en el caso que aquí se discutirá brevemente. El turismo depende de procesos de exclusión y segregación territorial que construyen el entorno de forma tal que la oferta turística se despliegue sin obstáculos y el consumo del paisaje se organice sin fricciones sociales. En lo que sigue, se revisarán tres formas 
en que se da tal proceso de producción del paisaje turístico: el establecimiento de un marco legal de propiedad que permite privatizar áreas y establecer zonas de exclusión y acumulación centradas en el turismo; la creación de infraestructura que da acceso y servicio a esas áreas exclusivas y atiende mayoritariamente sus necesidades y, por último, el establecimiento de regulaciones ambientales orientadas a preservar el paisaje solo en favor del turismo, sin una clara articulación con las necesidades y expectativas de desarrollo de las comunidades locales.

\section{El turismo es un proyecto de Estado}

La incertidumbre es un aspecto importante del turismo cuando se lo ve desde la perspectiva de las comunidades que, por su localización, por cambios en las demandas del mercado o por su riqueza biocultural, se incorporan a alguno de los circuitos en los que se organiza la economía turística global (MCKERCHER; LEW, 2004). Desde el punto de vista local el turismo es incierto, ya que depende de factores difícilmente regulables como el valor o calidad del paisaje y el ritmo de las corrientes de sargazo, la pureza del ambiente y la abundancia de recursos. Más aun, el turismo depende también de estrategias de apertura y promoción controladas por agencias y redes que operan con independencia de las poblaciones locales (BIANCHI, 2002). Una parte importante de la incertidumbre que caracteriza a la economía turística deriva también de la especial tensión entre formas de consumo potencialmente depredatorio, su carácter excluyente y su dependencia del paisaje biocultural sobre el que inevitablemente impacta. En este sentido, el desarrollo turístico instaura una dinámica que destruye aquello que lo sostiene (GOSSLING; HALL, 2016). Se trata de un proceso que, desde principios de la década de 1980, ha sido naturalizado por los 
teóricos y promotores turísticos quienes eufemísticamente se refieren a un cierto "ciclo de vida” de los destinos turísticos (BUTLER, 1980). Cuando un destino turístico ha "madurado" pierde atractivo a los ojos de promotores, agencias y los propios turistas; entonces las construcciones envejecen y se desmoronan, las infraestructuras decaen y ya no resultan atractivas para los inversionistas. Pareciera más bien un ciclo de muerte.

Un destino turístico es un espacio en constante transformación. Lo constituyen relaciones de acceso, proximidad, transitabilidad, propiedad, trabajo y consumo, que organizan con mayor o menor dificultad redes de servicios de alojamiento temporal, comida y esparcimiento incrustadas o enganchadas en entornos biofísicos dinámicos que, junto con la cultura local, sostienen la economía turística (STONICH, 1998; WILLIAMS, 2004). Por “economía” aquí se entiende el sistema que organiza y regula la explotación de los paisajes bioculturales. Teóricamente se puede pensar que la economía del turismo podría ser más o menos rica o depredatoria, equilibrada o desigual y expoliativa, sin embargo una extensa bibliografía basada en estudios empíricos muestra que, a pesar de los ingentes volúmenes de recursos financieros y humanos que organiza el turismo, se trata de un sector cuyos impactos negativos son relevantes (WONG, 2004). El caso de México, donde el turismo se convirtió en estrategia de desarrollo hace poco más de cincuenta años, se implantaron enclaves (destinos estratégicos, llamados Centros Integralmente Planeados) en diversos puntos del extenso y rico litoral del país. ${ }^{1}$ No es el objetivo de este trabajo sostener

\footnotetext{
${ }^{1}$ Centros turísticos que, como su nombre lo indica, fueron totalmente planificados por la Secretaría de Turismo y gestionados por el Fondo Nacional de Fomento al Turismo. Desarrollados alrededor de grandes hoteles de corporaciones internacionales, estos complejos incluyeron la planeación de los asentamientos urbanos tanto para los trabajadores como para el desarrollo inmobiliario de residencias vacacionales.
} 
que el turismo genera invariablemente marginación, sino explorar los procesos o mecanismos - que nada tienen de "natural" - que hacen que esto sea así.

El turismo es un fenómeno moderno (URRY, 1990), aunque no fue sino hasta mediados del siglo pasado que comenzó a adoptar las proporciones de un sistema que organiza las trayectorias de millones de personas a lo largo y ancho del planeta (SMITH, 2004). La experiencia casual de la que gozan un número cada vez más grande de turistas por todo el planeta depende de un gigantesco andamiaje de leyes y acuerdos, de tecnologías e infraestructuras, de escuelas y trabajadores, de agencias de publicidad, aviones y carreteras. En México, como en muchos otros países del sur global, todo esto ha sido posible gracias al continuo apalancamiento político y financiero de agencias internacionales como el Banco Interamericano de Desarrollo, el Banco Mundial o la Organización Internacional del Turismo, y al esfuerzo sostenido de gobiernos regionales y nacionales convencidos de que el turismo no solo es una gran oportunidad de negocio, sino también una estrategia de desarrollo. Desde una perspectiva crítica, esta idea ha sido cuestionada y el turismo se vincula con la creación de relaciones de dependencia entre centros metropolitanos dominantes y destinos periféricos más débiles y subordinados (BIANCHI, 2002).

Hoy en día, en aquellos contextos en los que se han implantado ya las condiciones de conectividad para el acceso continuo de cientos de miles de personas a regiones otrora remotas, el problema es cómo se distribuyen los beneficios y los costos sociales y ambientales. En el contexto mexicano, abordar este problema requiere poner atención en la acción del Estado y sus formas de planeación e intervención en el territorio.

Desde hace al menos una década, en México, el turismo se ubi- 
ca entre los tres sectores más importantes de la economía (ALTES, 2008). Esto es así debido a que, desde finales de los años 1960 del siglo pasado en adelante, los sucesivos gobiernos han invertido enormes cantidades de dinero y otros recursos públicos para abrir y organizar el territorio para su expansión bajo el principio de que se trata de una estrategia fundamental de desarrollo. Sin embargo, las estrategias de desarrollo del estado mexicano son cuestionables. Algunos puntos clave al respecto son: la preponderancia de una definición estrecha de desarrollo y de bienestar alineados a los principios y valores cosmopolitas y occidentales; la promoción de múltiples tipos de dependencia entre regiones centrales y periféricas; la ausencia de atención a la historia local y regional; la promoción de burocracias especializadas y de relaciones clientelares; la conceptualización del espacio en términos de extensiones abstractas e intercambiables y, por supuesto, la mercantilización de los paisajes bioculturales (MOSTAFANEZAH et al., 2016). Dadas estas tendencias generales, no debería resultar sorprendente que, de acuerdo con las propias agencias y organizaciones que promueven la expansión del turismo, entre los retos fundamentales están la participación de las comunidades locales en sus beneficios y la sostenibilidad ambiental de los destinos (OECD, 2006; MADRID; CASAR, 2018).

Visto desde la perspectiva del modelo mexicano, los problemas de captación de los beneficios y mejora de la calidad de vida de las poblaciones locales están íntimamente ligados a la intervención del Estado. Desde el inicio y a pesar de su envoltura social, la inversión de sucesivos gobiernos en favor del turismo ha privilegiado los intereses y negocios entre élites regionales, nacionales e internacionales a costa de la explotación de los territorios y el trabajo de la población local. La ideación, construcción y promoción de los cinco grandes enclaves, 
“Centros Integralmente Planeados”, insertados en puntos de gran valor natural y paisajístico del extenso litoral mexicano (Los Cabos y Loreto en Baja California, Can Cun en Quintana Roo, Ixtapa en Guerrero y Bahías de Huatulco en Oaxaca) es el epítome de un proyecto de estado que como modelo de negocios y promoción turística ha tenido éxito indiscutible, pero que excluye y desplaza a la mayoría de la población local de los beneficios. En las regiones periféricas, ahí donde el turismo ha pasado a convertirse y se presenta como la única alternativa de desarrollo, un primer paso para la creación de enclaves fue la preparación del terreno mediante reformas a la propiedad de la tierra; siguió la implantación de una infraestructura orientada exclusivamente a la actividad turística y, más recientemente, se integró el mecanismo de la regulación ambiental. Son estos los tres ejes que se discutirán más adelante dado que, aunque no abarcan por completo las dimensiones o procesos mediante los cuales se producen los destinos turísticos, permiten vislumbrar cómo el turismo se convierte, efectivamente, en un arreglo económico y político que excluye a ciertos grupos de los beneficios al tiempo que promueve los intereses de otros, más bien minoritarios y en su mayor parte externos a los territorios que afecta. ${ }^{2}$

En las tres últimas décadas, la costa sur de Oaxaca se ha convertido en un destino turístico nacional e internacional que atrae decenas de miles de visitantes al año. Los poco más de 160 kilómetros de la carretera costera que conectan los dos principales polos de atracción del corredor turístico, Puerto Escondido y Bahías de Huatulco, atraviesan algunas pocas planicies y cortan el agreste paisaje compuesto de una secuencia más o menos continua de bahías y playas, densa vegetación

\footnotetext{
${ }^{2}$ Son referencias relevantes sobre estos ejes Wolf (1972), Ferguson (1998), Escobar (1998) y Dominguez (2001).
} 
y poblados poco pintorescos y en algunos casos definitivamente pobres. Una carretera que corre paralela a la costa conecta una multitud de pequeñas localidades y rancherías con los pueblos situados en el pie de monte donde se organiza el mercado y la administración. Sobre esta vía corren taxis a toda velocidad y transitan camionetas que ofrecen servicio de transporte colectivo a una población bastante diversa de comerciantes, estudiantes, empleados de hoteles, restaurantes y casas de descanso, campesinos, artesanos, mochileros e inmigrantes de diverso tipo y nacionalidad. Esa vía es punto de acceso y motor de una economía turística bastante diversificada que crece y se expande con fuerza reconfigurando las relaciones territoriales, políticas y económicas en toda la región.

Este trabajo se centra en un grupo de poblados de la costa de Oaxaca, al sur de México. Se trata de sitios que han pasado a formar parte del corredor turístico que va desde Puerto Escondido, al noroeste en la frontera con el estado de Guerrero, hasta el "Centro Integralmente Planeado” Bahías de Huatulco y su aeropuerto internacional, 160 km al sureste por la autopista costera 200. La discusión que sigue deriva de un proyecto de investigación sobre turismo y cambios ambientales realizado entre 2012 y 2018. La mayor parte de la información se obtuvo en campo mediante talleres, mapeos colectivos y entrevistas con residentes de las localidades (RUBIO, 2014; 2017; 2018). Entre los poblados que aquí interesan, se destaca Puerto Ángel, una localidad de 2576 habitantes, ${ }^{3}$ que es uno de los centros pesqueros importantes de la zona con 250 embarcaciones y 13 cooperativas que agrupan alrededor de 700 pescadores. Con su hermosa bahía y su pequeño muelle del siglo XIX, hasta aquí llegó desde aquel entonces y aún antes uno

\footnotetext{
${ }^{3}$ México en cifras, Instituto Nacional de Estadística y Geografía. Web: https://www.inegi.org.mx/app/areasgeograficas/?ag=20
} 
de los caminos que unían, atravesando la Sierra Madre del Sur, la costa y la capital del estado. Este camino, por donde salía el café cuya producción alguna vez dominó la cercana región montañosa, fue una de las puertas de entrada del turismo. Anexo a Puerto Ángel, separados por un risco, se encuentra Playa Zipolite, una localidad de 1079 habitantes dedicada por completo al turismo, como los dos siguientes poblados, San Agustinillo y Mazunte, aunque en éstas dos, la actividad pesquera es todavía visible y relevante. Si bien muchos de los solares aledaños a la playa son o fueron propiedad de familias dedicadas a la pesca, la mayor parte de los dueños de la franja de tierra que poco a poco se va incorporando al circuito turístico tienen un origen campesino. Dado que la Sierra Madre del Sur se sitúa muy cerca de océano Pacífico, la planicie costera es muy angosta y en algunos tramos desaparece, por lo que la expansión del turismo rápidamente ha presionado sobre todo a la agricultura de temporal centrada en el maíz que con dificultad y poco apoyo institucional aún se practica en la región. Finalmente es preciso reparar que el corredor turístico colinda con los territorios de los pueblos indígenas Zapotecos del sur y Chontales de Oaxaca (BOEGE, 2008, p. 218-9) y San Pedro Pochutla agrupa población náhuatl, lo que es indicativo de la complejidad socio cultural de la costa oaxaqueña.

De acuerdo con la memoria local, desde Puerto Ángel llegaron las primeras 4 familias que se asentaron en la Playa Zipolite. Junto con Puerto Escondido, Puerto Ángel y Zipolite fueron localidades pioneras en recibir visitantes desde la década de 1970 aunque han mantenido un perfil de turismo alternativo y, hasta mediados de la década de 1990, con muy bajo nivel de capitalización (RUBIO, 2017, p. 105-6). $\mathrm{Al}$ poner atención en la experiencia de estas localidades resulta evidente, como se mostrará más adelante, que la implantación del pro- 
yecto de desarrollo turístico se hizo en el marco de un conflicto por el territorio y las playas, a veces soterrado y a veces abierto, que ha adoptado diversas formas y que aún hoy está vigente. Esta lucha se refiere al deslinde entre lo público, lo colectivo, lo comunal y lo privado; a la extensión y control de los servicios públicos; a la regulación y la política ambiental; al valor y titularidad de los recursos; a la definición de riesgos y la distribución de daños. Se trata, por lo tanto, de una lucha que involucra centralmente al Estado en sus múltiples y contradictorios papeles: promotor del desarrollo social; desarrollador inmobiliario; constructor y policía ambiental entre otros.

\section{Primera exclusión: la propiedad}

Para exponer el aspecto territorial de la economía política del turismo, me centraré en el caso específico de una localidad pionera en recibir turistas en la costa de Oaxaca: Zipolite. La memoria local indica que las primeras familias se asentaron en esta breve planicie costera en los años cincuenta del siglo pasado provenientes del vecino poblado de Puerto Ángel. La formación del asentamiento fue parte del más amplio proceso de colonización que se produjo entre mediados de la década de 1930 y 1960 en toda la región sur. Lo impulsaban campesinos de subsistencia en el marco de una lucha agraria que, en la costa de Oaxaca, se extendió hasta los años ochenta (BOTEY et al., 1989; REINA et al., 1988).

La colonización fue un proceso socio ambientalmente arduo. Muchos de estos colonizadores no eran pescadores sino campesinos sin tierra o trabajadores de ranchos con cuyos dueños mantenían relaciones clientelares que, comúnmente, se expresan en términos de lazos familiares. La familia extensa constituyó la forma de organización de 
los primeros residentes y un vínculo relevante entre Zipolite, Puerto Ángel y la cabecera del municipio San Pedro Pochutla. Hasta la década de 1980, la distribución y circulación de terrenos fue medida por redes personalistas y de parentesco que aún hoy juegan un papel importante en las decisiones sobre la gestión pública en la localidad.

En lo que se refiere a los mecanismos de exclusión que operan en la conformación del espacio del turismo, resulta importante el hecho de que la formación de Zipolite y la distribución original de derechos sobre el terreno estuvieron marcados por un complejo proceso agrario que inició el 18 de marzo de 1953 cuando el Estado reconoció los bienes territoriales de la comunidad de San Pedro Pochutla. ${ }^{4}$ En junio de aquel año se hizo pública oficialmente la posesión de 73,978 hectáreas de terreno a la comunidad indígena cuya autoridad es una asamblea actualmente formada por alrededor de dos mil quinientos comuneros. La delimitación de ese territorio se realizó a finales de 1970, casi dos décadas después. El retraso tuvo varias causas entre las que se cuentan el tortuguismo característico de la Reforma Agraria; la ausencia de información clara sobre las características del terreno y la falta de

\footnotetext{
${ }^{4}$ El reparto de tierra en México inició oficialmente con la Ley Agraria del 15 de enero de 1915, al calor de la Revolución y concluyó en 1992 con la Reforma al artículo 27 constitucional. En ese período, sobre todo después de 1932 cuando apareció el Código Agrario, se repartieron más de 100 millones de hectáreas y se establecieron alrededor de 30 mil ejidos y comunidades agrarias que fueron las unidades territoriales en las que se organizó la distribución de la tierra. En el caso de las comunidades el Estado reconocía derechos territoriales previos de los pueblos o comunidades indígenas, mientras en el caso de los ejidos se formaba una nueva unidad de población campesina. En ambos casos, la entidad a la que se otorgaba la tierra era a la comunidad o al ejido, formados por familias cuya cabeza detentaba el derecho de cultivar una parcela o de acceder a las tierras comunes. Hasta el fin del reparto, comuneros y ejidatarios tenían derecho de ocupar y explotar terrenos, pero no de rentarlos o venderlos, y sólo uno de sus descendientes podía heredar el reconocimiento como ejidatario o comunero. A pesar de las restricciones al "dominio pleno” de la tierra, en la práctica el fraccionamiento fue muy común, y dio lugar al extendido minifundismo muy presente en campo mexicano.
} 
recursos técnicos para producir dicha información; también tuvieron que ver los sucesivos conflictos de linderos entre diversas comunidades que reclamaban tierra. ${ }^{5}$

El año 1970 fue clave en la historia de Zipolite por tres motivos. El primero es que, como se mencionó ya, en noviembre de ese año se delimitó el territorio de la comunidad de Pochutla. El segundo es que en marzo un gran eclipse solar fue la ocasión para que esa parte aislada de la costa de Oaxaca recibiera atención nacional e internacional haciendo que Puerto Ángel y Zipolite fueron visitadas por gente muy diversa, desde misiones universitarias de investigación e ingenieros civiles, hasta jóvenes trotamundos y místicos. El tercer motivo es que, paralelamente a la delimitación, el gobierno del estado de Oaxaca expropió la franja costera de los bienes comunales (1,560 hectáreas, incluyendo Zipolite) para formar el Fundo de Desarrollo Turístico e Industrial de Puerto Ángel y Anexos.

Cuando el gobierno estatal expropió la costa a San Pedro Pochutla, la idea de crear enclaves turísticos en puntos estratégicos y aislados del territorio, entre los que se divisaba la costa oaxaqueña, ya se había puesto en marcha a nivel federal. Comenzó entonces la historia oficial del turismo en la zona mediante un acto expropiatorio que sacaba de en medio a la población local. Con rapidéz, el Fundo puso en venta la franja de tierra que hace la breve planicie costera a empresarios, rancheros y políticos a quienes los residentes de Zipolite y poco después

\footnotetext{
${ }^{5}$ Este tipo de problemas fueron comunes a lo largo de toda la Reforma Agraria en todo el país. No detuvieron el proceso de colonización, pero lo volvieron turbulento y problemático. En las distintas regiones del país, el éxito del reparto agrario dependió en gran medida de la relación de fuerzas entre poblados, caciques, comunidades y terratenientes; con todo, la Reforma Agraria en México distribuyó poco más de la mitad del territorio. La gran cantidad de tierra distribuida es testigo del enorme capital social de las comunidades campesinas que gestionaron el reparto (MANZANILLA-SCHAFFER, 2004).
} 
el resto de los comuneros de Pochutla no tardaron en disputar la playa.

A mediados de 1976, la negativa de uno de los nuevos propietarios privados del Fundo para ceder un terreno para una escuela, dio pie a un conflicto que fue escalando hasta involucrar la movilización del ejército para “resguardar la seguridad en la zona”. Para ese entonces las irregularidades técnicas y legales en una expropiación que violaba el principio de inafectabilidad de la propiedad comunal asentado en la Constitución, ponían en cuestionamiento la legalidad del Fundo. De acuerdo con un participante en el conflicto, la gente de Zipolite logró obtener el apoyo de diversas organizaciones campesinas estatales y nacionales, así como de productores y comerciantes de la región quienes financiaron tanto las gestiones legales como una campaña de denuncia que, hacia julio de 1979, llegó a los periódicos nacionales. Esos eran años de mucha conflictividad social sobre todo en zonas rurales, aunque la política y el discurso agrarista aún resonaban en el repertorio nacionalista del estado mexicano. La escalada mediática que llegó a involucrar a un secretario de estado y exgobernador de Oaxaca en una expropiación ilegal y al ejército en la represión de campesinos buscando educación, propició la intervención del gobierno federal que anuló la expropiación, extinguió el Fundo y ordenó la devolución de las tierras a la comunidad de Pochutla. El desmantelamiento del Fundo dio lugar a un reparto de los terrenos de Zipolite entre viejos y nuevos comuneros, además de la consolidación, a partir de los grandes lotes recuperados, de las colonias que colindan con la playa (Roca Blanca, Palmas, Playa del amor y Centro), que son las que concentran la oferta turística y cuentan hoy con los mejores servicios. Por otra parte, algunos kilómetros más al este sobre la costa, la federación estableció el proyecto integralmente planeado Bahías de Huatulco que hoy es uno de los destinos estratégicos del país y uno de 
los puntos desde el que la economía turística se va expandiendo con rapidez sobre la costa oaxaqueña.

En 1991 se reformó la Constitución, se terminó el reparto de tierra, se modificó el régimen de propiedad social, se modernizó el catastro y se promovió la regularización y titulación de los terrenos (PEREZ, 2002). Aunque paulatino, este cambio tuvo un impacto importante, y abrió la posibilidad de trasparentar y facilitar las transacciones de compraventa aún dentro de las comunidades agrarias. Con los años, en Zipolite las familias crecieron y el proceso de lotificación y expansión de la mancha urbana se aceleró. La enmienda dinamizó los intercambios e incrementó el atractivo y seguridad de tal forma que cada vez más foráneos han podido establecer una residencia temporal o un negocio en el área urbana ahora definida con mayor claridad.

El conflicto por la propiedad de la tierra y las playas en Zipolite revela cómo la maquinaria técnico-administrativa, la planeación y el ejercicio de la fuerza, dieron forma autoritaria al proyecto turístico oficial. Es importante subrayar que el conflicto entre la comunidad de San Pedro Pochutla y el Fundo para el desarrollo turístico mostró con excepcional claridad un asunto esencial: que las comunidades locales lucharon desde un inicio contra su exclusión del programa turístico.

\section{Segunda exclusión: la infraestructura}

De los cinco complejos “integralmente planeados” que constituyen la plataforma estratégica del desarrollo turístico en México, Huatulco fue el que más tardó en consolidarse. Esto puede relacionarse con varias cosas, como las particulares dificultades geográficas que representó su construcción o la resistencia social que enfrentó el proyecto por parte de las comunidades locales como fue el caso de Co- 
yula (TALLEDOS, 2012) o el ya mencionado conflicto con el Fundo promovido por el gobierno estatal. El desarrollo de turístico de la costa oaxaqueña requirió además una gran inversión pública para abrir y organizar el territorio. Hasta 1960 las comunicaciones en la costa oaxaqueña estaban centradas en el trasiego de materias primas (principalmente café) acaparadas sobre todo en los pequeños puertos de Puerto Ángel y en menor medida Huatulco y Puerto Escondido. Estos puntos organizaban el flujo, principalmente de salida, de mercancías y personas entre la sierra, donde se asientan los pueblos más densamente poblados que concentraban la administración y el comercio, y la costa. La comunicación por tierra entre las rancherías del litoral se componía de sendas, veredas y algunos caminos de terracería. A principios de los 1980 en esa región aislada del centro aunque integrada regionalmente y para nada deshabitada, irrumpieron dos aeropuertos y se construyó un tramo de la carretera costera conectando Puerto Escondido con Huatulco (1983). A medio camino entre esos polos de desarrollo turístico, se encuentra San Pedro Pochutla, y cruza además el camino que llega hasta Puerto Ángel e inmediatamente después a Zipolite, Mazunte y otras localidades que hoy se sostienen de los turistas. A partir de 1993, año en que se asfaltó este último camino, el flujo de turistas se ha incrementado y diversificado visiblemente en casi toda la franja de la costa.

La implantación de dos grandes accesos produjo los esperables cambios en la organización general del territorio. La larga relación sierra-costa, en la que la primera concentra el control político y administrativo, está sujeta ahora a tensiones que antes no existían. Aun hoy, tres de las cinco cabeceras municipales del corredor (Mixtepec, Colotepec y Tonameca) están pobremente conectadas con la línea de costa donde proliferan hoteles, casas y ranchos de descanso. Es limitado el 
control que son capaces de ejercer los municipios sobre sus territorios, lo que tiene consecuencias negativas en cuanto a la distribución de beneficios, los servicios públicos, la planeación y la regulación. Emerge entonces una dinámica centrífuga que tiende a separar la franja costera del resto del territorio.

Sin lugar a dudas no es esta la historia de un área territorialmente integrada que de pronto se vio fracturada por el turismo. Tratándose de una región multicultural en la cual prosperó durante al menos un siglo la economía cafetalera, en la cual los centros urbanos concentraban a la población blanca y mestiza que dominaba a las comunidades indígenas dispersas en la sierra, las inequidades espaciales han sido una constante. La Reforma Agraria matizó las desigualdades y otorgó mayor capacidad de control a las comunidades, aunque no eliminó la marginalidad de la mayoría de la población. Sin embargo, las grandes inversiones que abrieron el territorio con la promesa de un nuevo desarrollo basado en el turismo, tampoco hicieron justicia a los desposeídos, sino que sumaron a las antiguas inequidades espaciales otras nuevas al tiempo que permitieron la llegada de nuevos grupos de interés escasamente vinculados con los poblados de larga data. Por una parte las grandes infraestructuras reformularon las diferencias intrarregionales, desplazando hacia la periferia a las poblaciones serranas y reordenando las relaciones de interdependencia entre localidades. Por la otra, la inversión en servicios (saneamiento, electricidad, salud, educación, etc.) concentrada en unos cuantos puntos estratégicos, ha generado un intenso proceso de segregación. Aunque suene paradójico tratándose de poblaciones más bien pequeñas, aparecen barriadas marginales en las localidades turísticas y surgen rancherías y precarios asentamientos en los linderos de las autopistas, mientras los pequeños centros urbanos gozan de constantes renovaciones e inversiones para 
mejorar la imagen urbana y la dotación de servicios para una población turística flotante, cuyos patrones de consumo presionan constantemente a las agencias municipales para atender sus demandas o hacen inversiones sólo en su propio beneficio.

Además de las grandes infraestructuras, desde que el turismo se instauró la mayoría de las inversiones en servicios (agua potable y saneamiento, mejoras en el equipamiento urbano, electricidad y telecomunicaciones) han quedado sistemáticamente supeditadas a mejorar la oferta. Así también sucedió con la creación de la Universidad del Mar, que si bien responde a una demanda social de acceso a la educación, está orientada fundamentalmente a capacitar la fuerza de trabajo, mejorar la administración y, secundariamente, a formar capacidades para un mejor manejo de los recursos marinos.

\section{Tercera exclusión: la política ambiental}

Quienes conocieron la región a principios de la década de 1980 pueden recordar la costa de Oaxaca como un jardín donde el mar y los manglares ofrecían un delicioso alivio de la dureza del bosque seco. Muchas de las playas, todavía hermosas, no son más el hogar de cangrejos, langostas y pulpos, incluso los peces se han retirado. Esta es una apreciación intuitiva de primera mano y algo que surgió en numerosas conversaciones y entrevistas con informantes muy diversos. $\mathrm{Y}$ aunque no hay duda de que el desgaste de la costa tiene que ver con la llegada del turismo, se trata de un problema que tiene antecedentes.

En la década de 1950, los primeros esfuerzos de desarrollo ideados por el Estado para la región se centraron en la explotación de los recursos marinos. El gobierno federal construyó una planta de procesamiento de pescado en Puerto Ángel (1970), a la que vendían sus 
capturas cooperativas pesqueras de diversos puntos de la costa. En las cercanías del pequeño poblado de San Agustinillo - hoy totalmente reconvertido para el turismo -, se instaló un matadero de tortugas. Se trataba de un negocio privado que en 1979 empleaba a 200 personas para la producción de aceite para exportación. La voracidad de esta industria llevó a la casi completa desaparición de las tortugas en la zona.

Tradicionalmente, las tortugas golfinas forman parte de la dieta local. Los pueblos indígenas de la zona (chantinos, zapotecas, nahuas) han coexistido con las tortugas durante siglos. De hecho, las tortugas son parte de la memoria paradisíaca de Zipolite y de toda la costa de Oaxaca. Sin embargo, los colonizadores que se establecieron en la playa desde mediados de la década de 1950 no pudieron regular o al menos mitigar el frenesí extractivo alimentado y monopolizado por la industria del aceite de tortuga durante los casi veinte años que duró la explotación irrestricta. Nada de la riqueza que esta industria produjo se invirtió en la región. No hay carreteras, ni servicios, ni siquiera el edificio donde operaba el matadero permanece en pie. Cuando las tortugas estaban al borde de la extinción, el estado adquirió el matadero y lo transfirió a la cooperativa local de pescadores. Finalmente, el edificio cerró en 1994.

La incapacidad para regular la captura de tortugas y la sustracción de huevos tenía que ver con el carácter público de la playa donde las tortugas llegan a anidar. La ley mexicana considera los primeros 20 metros de playa como terreno nacional que no puede ser ocupado ni privatizado, y cuya vigilancia y cuidado dependen del gobierno federal. Dada la muy limitada capacidad de la federación de hacerse cargo de esa franja a lo largo y ancho del país, las playas en México siempre corren el riesgo de caer en una tragedia de los comunes. Tal fue el 
caso de las tortugas en la costa de Oaxaca. El arreglo institucional (OSTROM, 1990) en su conjunto propiciaba un uso irracional del recurso: las autoridades comunales locales eran de tipo agrario y no podían reclamar derechos de explotación ni controlar a quienes recorrían las playas cazando de tortugas y saqueando nidos; las cooperativas pesqueras tenían muy pocos recursos institucionales y materiales para, siquiera, llevar un registro del volumen de explotación; la ausencia de regulación y vigilancia federal generaba un vacío de autoridad, mientras que, finalmente, había un actor poderoso - el negocio privado del matadero - capaz de apropiarse del recurso y de acelerar su extracción hasta el agotamiento ofreciendo salarios de hambre. La masacre de las tortugas golfinas ofrece un ejemplo dramático de lo que sucede cuando, con el apoyo tácito o explícito del Estado, se permite que un solo agente se apodere y explote sin freno los recursos comunes de toda una región (CLEAVER, 2000).

La situación cambió a principios de la década de 1990, cuando se creó la Secretaría de Medio Ambiente y Pesca. En 1994, esa institución emitió una prohibición sobre la captura de tortugas y se puso al frente de la campaña por protegerlas. Se instalaron campamentos de reproducción en toda la región costera y se construyó un Museo de Tortugas con fondos públicos en Mazunte, una localidad a solo 10 minutos de Zipolite. La casi extinción de las tortugas fue una crisis ambiental que dio cierto carácter al turismo en Oaxaca. Ayudar a las tortugas a llegar al mar se convirtió en un motivo central de toda una eco imaginería. La prohibición de su captura y comercio y otras políticas de protección, como la creación del Parque Nacional Bahías de Huatulco, introdujeron la sustentabilidad en la política turística general. La protección ambiental se convirtió en un atractivo más de la zona, sin embargo sus efectos en las alternativas de vida de los habi- 
tantes locales no fueron homogéneos. Las vedas y el establecimiento de parques nacionales, junto con la privatización de los recursos que pueden ser legalmente explotados, afectan desproporcionadamente a las cooperativas pesqueras y a los agricultores sin que las acciones gubernamentales contemplen algún tipo de reparación o asistencia. Además de desplazar a los márgenes actividades productivas alternativas al turismo, una perspectiva excluyente de la conservación impone el rol de guardián a la población local sin que necesariamente sea ésta misma población la que recibe la mayor parte de los beneficios (RUBIO, 2018).

\section{A manera de conclusión: Un proyecto de desarrollo desigual}

A los tres ejes de transformación anteriores se pueden sumar otros para ahondar la caracterización de la recomposición social, ambiental y espacial de la costa de Oaxaca asociada con la implantación del turismo como motor de la economía regional. El desplazamiento de la frágil agricultura de temporal, el narcotráfico y el tráfico de personas, los pequeños y grandes desastres que año con año afectan una u otra localidad incrementando la fragilidad socio ambiental en general; la conflictiva recomposición de las relaciones inter e intraétnicas; el cambio demográfico o la especulación inmobiliaria desenfrenada, son otros temas que valdría la pena explorar con detenimiento. Sin embargo, la regulación de la propiedad, la inversión en infraestructura y la política ambiental, permiten corroborar que:

1) La dinámica extractivista y depredatoria que adopta el turismo en los espacios periféricos que van siendo incorporados vertiginosamente al sistema global, ha requerido y requiere aún del apalan- 
camiento gubernamental y, por ello, es en parte el resultado de una política de Estado.

2) En su carácter desarrollista, esa política ha pasado por excluir a los actores locales de los beneficios del propio proyecto de "desarrollo" y pugna por transformarlos en servidores de intereses extraregionales y en clientes de las agencias gubernamentales.

3) El turismo ha descompuesto las viejas relaciones de dominio e interdependencia entre grupos y lugares, instaurando otras nuevas en las que el elemento "ambiental” ha sido convertido decididamente en mercancía y alimenta la narrativa excluyente.

4) Se ha dividido la región y se ha erosionado la red de relaciones socio-productivas (también políticas y culturales) que, sin dejar de ser conflictivas, unificaban el paisaje de la costa con el de la sierra. La playa es un espacio de inversión privada al que la comunidad ha quedado subordinada.

El modelo de desarrollo turístico crea resistencias al orden general que se va estableciendo. Éstas pueden adoptar la forma de lucha abierta por recuperar el espacio, por gestionar servicios o demandar acceso a la infraestructura y a los beneficios que atienden la demanda turística. Experiencias de organización como las cooperativas, o los ordenamientos territoriales comunitarios o las campañas de saneamiento, dan cuenta de que las poblaciones locales - a veces con la ayuda de los propios turistas - buscan capturar, contener y orientar la fuerza potencialmente devastadora del turismo. En general, la lucha se da por la apropiación del turismo y de los recursos que produce y, es preciso tal vez aclararlo, no en contra de la llegada de visitantes o extraños.

Frente a las muchas preguntas que plantea el turismo, en este trabajo se ha buscado hacer un aporte a la respuesta sobre cómo se construyen y sostienen las condiciones para que una actividad que depende en gran medida del entorno biocultural común y compartido, produzca ganancias y cómo se distribuyen los costos. La respuesta ha sido 
que la implantación y el crecimiento del turismo se produce mediante la exclusión de gran parte de la población local de los beneficios, y la reorientación violenta de su fuerza de trabajo y sus recursos culturales hacia la atención de visitantes y la producción de un paisaje-mercancía susceptible de ser consumido y al que se le puede extraer ganancia.

\section{Referencias}

ALTES, Carmen. Turismo y desarrollo en México. Nota sectorial. [s.l.].: Banco Interamericano de Desarrollo, 2008. Disponible en: publications.iadb.org Acceso el 10 dic. 2019.

BIANCHI, Raoul. Towards a new political economy of global tourism. In: SHARPLEY Richard; TELFER David (eds.). Tourism and development: concepts and issues. Clevendon: Channel View Publications, 2002. p. 265299.

BOEGE, Eckart. El patrimonio biocultural de los pueblos indígenas de México. México: Instituto Nacional de Antropología e Historia - Comisión Nacional para el Desarrollo de los Pueblos Indígenas, 2008.

BOTEY, Carlota et al. Historia de la cuestión agraria mexicana. México, Siglo XXI-CEHAM, 1989.

BUTLER, Richard. The concept of a tourist area cycle of evolution: implications for management of resources. Canadian Geographer, 24 (1), 1980, p. 5-12.

CLEAVER, Frances. Moral ecological rationality, institutions and the management of common property resources. Development and Change, n. 31, 2000, p. 361-83.

DOMINGUEZ, Juan Carlos. Megaproyectos, infraestructura y los límites de la democracia participativa. Revista Legislativa de Estudios Sociales y Opinión Pública, v. 4, n. 7, 2001, p. 33-62.

FERGUSON, James. The anti-politics machine. "Development” and bureaucratic power in Lesotho. The Ecologist, 24 (5), 1998, p. 176-81.

GOSSLING, Stephan; HALL, Michael. Tourism and global environmental 
change: ecological, economic, social and political interrelationships. Londres: Routledge. 2016.

INEGI. Instituto Nacional de Estadística y Geografía. México en cifras, Web: www.inegi.org.mx, fecha de acceso 25 mayo 2020.

MADRID, Francisco; CASAR José Ignacio. Turismo y desarrollo social: nuevas razones de Estado para una política turística. México, 2018. Disponible en: www.anahuac.mx Acceso: 10 dic. 2019.

MANZANILLA-SCHAFFER, Víctor. El drama de la tierra en México. Del siglo XVI al siglo XXI. México: SRA-UNAM-Miguel Angel Porrúa, 2004.

MCKERCHER, Bob; LEW, Alan. Tourist flows and the spatial distribution of tourists. In: LEW, Alan; HALL, Michael; WILLIAMS, Allan (eds.). A companion to tourism. Londres: Blackwell Publishing, 2004, p. 36-48.

MOSTAFANEZHAD, Mary et al. Introduction. In: MOSTAFANEZHAD, Mary et al. (eds.). Political ecology of tourism. Community, power and environment. Nueva York: Routledge, 2016. p. 1-21.

OECD. Estudio de política turística en México. Resumen ejecutivo, evaluación y recomendaciones. 2006. Disponible en: www.datatur.sectur.gob.mx Acceso: 10 dic. 2019.

OSTROM, Eleanor. Governing the commons: the evolution of institutions for collective action. Cambridge: Cambridge University Press, 1990.

PEREZ, Juan. El nuevo sistema de propiedad agraria en México. México: Textos y Contextos, 2002.

REINA, Leticia et al. Historia de la cuestión agraria mexicana Estado de Oaxaca. México: Juan Pablos Editores, Gobierno del estado de Oaxaca, UABJ, Centro de Estudios Históricos del Agrarismo en México, 1998.

RUBIO, Ignacio. Industrias turísticas y escenarios de desastre asociados al cambio climático en el litoral oaxaqueño. México: Programa de Investigación en Cambio Climático, UNAM, 2014.

. Un destino incierto. Expansión del turismo, daños y riesgos ambientales en la costa de Oaxaca. Acta Sociológica, n. 73, 2017, p. 83-122.

. Tourism, environmental damage, and climate policy at the coast of Oaxaca, México. In: KLEPP, Silja; CHAVEZ-RODRÍGUEZ, Libertad (eds.). A critical approach to climate change adaptation. Discourses, policies and 
practices. Londres: Routledge, 2018. p. 97-111.

SMITH, Stephen. The measurement of global tourism: old debates, new consensus, and continuing challenges. In: LEW, Alan; HALL, Michael; WILLIAMS, Allan (eds.). A companion to tourism. Londres: Blackwell, 2004. p. 23-35

STONICH, Susan. Political ecology of tourism. Annals of Tourism Research, 25, 1998, p. 25-54.

TALLEDOS, Edgar. La imposición de un espacio: de La Crucecita a Bahías de Huatulco. Revista Mexicana de Ciencias Políticas y Sociales, 57 (216), 2012, p. 119-42.

URRY, John. The tourist gaze. Londres: Sage, 1990.

WILLIAMS, Allan. Toward a political economy of tourism. In: LEW, Alan; HALL, Michael; WILLIAMS, Allan (eds.). A companion to tourism. Londres: Blackwell, 2004. p. 61-73.

WOLF, Eric. Ownership and Political Ecology. Anthropological Quarterly, 45 (3), 1972, p. 201-5.

WONG, P. P. Environmental impacts of tourism. In: LEW, Alan; HALL, Michael; WILLIAMS, Allan (eds.). A companion to tourism. Londres: Blackwell, 2004. p. 450-61. 


\section{Resumen:}

El turismo destaca como estrategia de desarrollo en el sur global aunque, de acuerdo con sus propios promotores, entre los problemas que plantea están la participación local en sus beneficios y la destrucción ambiental. El objetivo de este trabajo es mostrar que esos problemas no son fortuitos, sino que son resultado, al menos en parte, del carácter excluyente del proyecto de desarrollo turístico impulsado por el Estado. Tomando el caso de la costa del estado de Oaxaca en suroeste de México, se analizan tres mecanismos de exclusión: la intervención en el régimen de propiedad, la creación de infraestructura y la regulación ambiental. Además de confirmar la naturaleza excluyente del modelo turístico, el análisis permite entender la lógica de resistencia/aceptación de las comunidades y sugiere que solo la apropiación local logrará hacer del turismo una verdadera alternativa de desarrollo.

Palabras-clave: Ecología Política del Turismo; Desarrollo; Exclusión Socio Ambiental. 


\begin{abstract}
:
Tourism stands out as a development strategy in the global south. Yet, according to its own promoters, two of its central problems are lack of local participation in its benefits, and environmental destruction. The objective of this piece is to show that hose problems are nor fortuitous, and that despite its developmentalist overtones, they can be atribued to the touristic project envisaged by the state. Taking the case of a touristdominated region of the south of Mexico, three mechanisms of exclusion are analyzed: intervention in the property regime; creation of infrastructure and environmental regulation. In addition to confirming the exclusionary nature of the tourist enclave model, the analysis allows to understand the logic of resistance / acceptance of the communities and suggests that only local appropriation will make tourism a true development alternative.
\end{abstract}

Keywords: Political Ecology of Tourism; Development; Socio Environmental Exclusion. 